\title{
Determination of the primary technical parameters of the test bench for controlling the temperature of rails and rail bars of continuous welded rail
}

\author{
Vitalii Tertychnyi ${ }^{1}$, Glib Vatulia ${ }^{1, *}$, Oleksandr Belorusov ${ }^{1}$, and Maksym Kovalov ${ }^{1}$ \\ ${ }^{1}$ Ukrainian State University of Railway Transport, Structural Mechanics and Hydraulics Department, 7 Feuerbach Sq., \\ 61050 Kharkiv, Ukraine
}

\begin{abstract}
One of the most important factors determining the reliability and safety of operation of the continuous welded rail track is the temperature of the rails. All conditions of laying, repair and maintenance of the track during the entire cycle of rails operation depend on it. The existing rail temperature monitoring method does not take into account a few significant factors and that leads to significant errors in determining the actual temperature of the rail bar. The authors propose a new rail temperature measurement method on a special test bench which maximally simulates possible environmental operating conditions for the rail bars, the profile of the roadway (embankment or cut), as well as the actual spatial latitude and meridian location of the rail slabs. At the bench, the studied rails are fastened with the help of rail braces on half ties, in the ballast bed, with sizes in accordance with the existing reference documents. At the first stage, the most common KB-65 intermediate fastener for the continuous welded rail in Ukraine will be used, while in subsequent stages KPP-5 fastening will be used.
\end{abstract}

\section{Introduction}

With the increasing speed of the railway transport everywhere in the world and in Ukraine, in particular, significant upgrade of the rail infrastructure is required, especially through the arrangement of the continuous welded rail track $[1,2]$. However, during the operation, temperature variations cause considerable longitudinal forces and tensions in the rails. At present, there are numerous temperature monitoring and determination systems using a variety of non-destructive testing methods, each having both advantages and significant disadvantages [3-8].

According to [9], in Ukraine at all sections of the continuous welded track, the rail temperature should be continuously monitored directly at special temperature metering posts (or special benches located in latitudinal and meridional directions) of the track sections determined by the geophysical station of the railway. In most cases, these are guarded crossings, as well as benches of the meteorological stations of the railways. According to the requirements [10], the temperature post is half rail-track of the corresponding rail and tie type, the type of ballast bed used at the section, and consists of a short rail fixed on two half ties. All available means of rail temperature measurement provide for an alcohol thermometer hole drilled at the end of the rail head or on the working surface. In this case, the thermometer is covered with a special metal sheet casing to prevent sunlight exposure.

\section{Setting objectives}

It should be noted that most common benches used on the railways in Ukraine and in the CIS countries have significant disadvantages, such as:

- the whole range of the latitudinal and meridional positions of the rails on the lines cannot be taken into account;

- the specific configuration of the ballast bed (embankment or cut) cannot be taken into account;

- the natural heat transfer conditions existing in the rail bars both in the longitudinal direction and in the cross section cannot be taken into account;

- the conditions of heat transfer from the rails to the ballast bed are not taken into account;

- the condition of intermediate fasteners with regard to the tension of fasteners cannot be taken into account;

- the short rail length is not substantiated;

- the conditions of the heat transfer to the rails from the reflected solar radiation are not taken into account;

- heat transfer to the rails from the ballast bed ground cannot be taken into account;

In addition to the above given drawbacks, the principle of measurement in a single cross-section is not perfect, the thermal technical parameters of which fail to correspond to the reliable state of the railing bar [1,3-5]. This leads to an error in determining the rail bar temperature of $12 \div 15^{\circ} \mathrm{C}$, depending on the traction current type and operating mode (movement speed and intensity, axial loads, mode of movement or braking).

* Corresponding author: glebvatulya@gmail.com 
The test benches of the track sections are basically designed to collect the data on rail temperature changes in order to predict its value for scheduling track works and determine their working values based on the air temperature, adding the constant value $\Delta t=20^{\circ} \mathrm{C}$ to it (if the air temperature is above zero). This does not comply with the existing requirements to an improved track works practice, because it does not allow to determine the reliable values of the rail bar temperature in real operating conditions. For the routine maintenance or repair of the welded track, we need to know the temperature of the pre-weighed rail bars at the time of their laying and fixing for permanent operation or the carrying out of urgent, emergency works to eliminate track defects of geometric or physical origin.

\section{Determination of the factors influencing rail temperature}

Direct solar radiation, which is $90 \div 92 \%$ of the total heat flow, is known to be the main heat source for rail heating, while scattered solar radiation is about $8 \div 10 \%$. Scattered radiation reaches the entire free rail surface, while the direct one only the projection area of the rail normally oriented to the sun beams. In view of this fact and the size of modern ties, we can consider that part of the heat, which the rail receives from scattered radiation, to be up to $20 \div 25 \%$. Thus, the main factor influencing rail heating is latitudinal and meridional orientation of the short rails at the test bench, which is determined in four exposure options: Northern (N), Eastern (E), NorthEastern (N-E), South-Eastern (S-E). Scattered radiation is formed by the reflection of the sun beams from the grass, from the ballast bed surface, from the cut or embankment slopes, and only slightly from the trees or surrounding buildings and constructions (artificial constructions, platforms, overpass bridges, bridges, storehouses etc.).

Heat loss of the short rails at the test bench should correspond to the actual heat loss conditions of the existing track. For this purpose, the ends of short rails should be insulated by sticking foam polystyrene end insulation caps to them to prevent the rails from cooling on the ends and help to maintain a constant stable temperature of the entire short rail. Its actual (mean volume) temperature will be calculated based on the measurements of the prolonged short rail. Its length can be calculated using the formula (1) obtained from the known expression for determining free thermal distortion under exposure to heat

$$
l_{r c}=\frac{\Delta \varepsilon_{l}}{\Delta \varepsilon_{t}} \frac{n}{\alpha},
$$

where $\alpha=11,8 \times 10^{-6} 1 /{ }^{\circ} \mathrm{C}$ is the mean estimated value of the temperature coefficient of the linear heat expansion of rail steel [1,9]; $\Delta \varepsilon_{l}$ and $\Delta \varepsilon_{t}$ are errors in measurement of longitudinal and temperature prolongations; $n-$ number of devices for controlling temperature prolongations.
Calculation using the formula (1) determined that the length of the test rail should be not less than $1,5 \mathrm{~m}$.

According to the requirements of the regulatory document [9], the torque force on the terminal bolts of the intermediate rail fastening KB-65 should be at least $100 \mathrm{Nm}$, while on the insert bolts - at least $70 \mathrm{Nm}$.

We will accept the number of half-ties, type and thickness of the crashed stone ballast to be in accordance to the requirements [10]. It should be noted that the requirements [10] do not provide for any sand bed, but for the complete reproduction of the heat transfer conditions we arrange it as the rail pad with the standard thickness of $200 \mathrm{~mm}$.

To reproduce the solar radiation flow, we provide for creation of loam embankment (cut) slopes subsequently seeded with the grass.

To reproduce the intensity of the solar radiation reflected from the embankment or cut slopes, we assume for the test bench a similar steepness of 1:1,5.

To reproduce the heat transfer process from the rail to the air and ballast bed, we assume that the ballast section shoulder is $350 \mathrm{~mm}$.

The obtained principle technical parameters of the bench are summarized in Table 1. The embankment height and the cut depth at the test bench remain unspecified, since these parameters should be determined taking into account the requirements of the similarity theory [11] and the study of air flow modelling processes [12-14].

\section{Determination of the embankment height of the cut depth at the test bench}

The rail track is situated in ground atmospheric air, where wind velocity changes with height by logarithmic dependence, while the monthly mean velocities in the summer are $2 \div 4 \mathrm{~m} / \mathrm{s}$ [15].

Depending on the ballast bed configuration [2], slope steepness and orientation have significant impact on heat delivery to the earth's surface which affect the thermodynamic condition and the small scale climate of the entire slope area (cut and embankment slopes), and, respectively, affect the rail temperature [9]. Thus, the available data on snow-wind transfer should be analyzed, which were did in detail while designing the embankments and cuts in the most dangerous areas, with various models and aerodynamic benches [12-14].

In [15] it was demonstrated that the air flows around a separate $100 \mathrm{~mm}$ high hill with a base length of $1500 \mathrm{~mm}$, upper surface length of $500 \mathrm{~mm}$ and a span of $2000 \mathrm{~mm}$, enabled the detection of a very slight flow disturbance (turbulence). Similar results were obtained with slope surface angles of up to $15-20^{\circ}$. This shows that since the wind velocity above the rail track in the summer is much lower $(2 \div 4 \mathrm{~m} / \mathrm{s})$ as compared to that used with the model in the air tunnel $(20 \mathrm{~m} / \mathrm{s})$, even with steeper slopes the flow will have minor disturbances.

The railway designing guidelines set forth a minimum embankment height of $1,0 \mathrm{~m}$. The studies [12, 14] proved that with a cut slope of $30^{\circ}$, the wind velocity is $1,36 \%$ lower for each $100 \mathrm{~mm}$ of its 
Table 1. Principal technical parameters of the test bench for temperature measurement.

\begin{tabular}{|c|c|c|c|c|}
\hline No & Parameter & $\begin{array}{l}\text { Parameter value under the } \\
\text { natural conditions }\end{array}$ & $\begin{array}{l}\text { Parameter value } \\
\text { at the model }\end{array}$ & Determination method \\
\hline 1 & Rail type & R65 & R65 & Analogue is accepted \\
\hline 2 & Rail length & $250 \div 800 \mathrm{~m}$ & $\begin{array}{l}1,5 \mathrm{~m} \text { according to the } \\
\text { method }[10]\end{array}$ & $\begin{array}{l}\text { Calculation depends on the } \\
\text { accuracy of the determining } \\
\text { thermal distortion of the short rail }\end{array}$ \\
\hline 3 & $\begin{array}{l}\text { Intermediate rail } \\
\text { fasteners }\end{array}$ & KB-65 & KB-65 & Analogue is accepted [9] \\
\hline 4 & Tie & Sh $1-1$ concrete tie & $\begin{array}{l}1,0 \mathrm{~m} \text { long half-tie, three } \\
\text { half-ties }\end{array}$ & $\begin{array}{l}\text { Analogue for support of one rail is } \\
\text { accepted [10] }\end{array}$ \\
\hline 5 & Ballast & $\begin{array}{l}\text { Crushed stone } 25 \div 60 \mathrm{~mm} \text {, } \\
\text { layer thickness } 350 \mathrm{~mm}\end{array}$ & $\begin{array}{l}\text { Crushed stone } 25 \div 60 \mathrm{~mm} \text {, } \\
\text { layer thickness } 350 \mathrm{~mm}\end{array}$ & Analogue is accepted [9] \\
\hline 6 & Sand bed & Thickness 200 mm & Thickness 200 mm & Analogue is accepted [9] \\
\hline 7 & $\begin{array}{l}\text { Ballast bed } \\
\text { ground }\end{array}$ & Loam with humus & Loam with humus & Analogue is accepted [9] \\
\hline 8 & Ground surface & Grass seeding & Grass seeding & Analogue is accepted \\
\hline 9 & Slope steepness & $1: 1,5$ & $1: 1,5$ & Analogue is accepted [9] \\
\hline 10 & $\begin{array}{l}\text { Embankment } \\
\text { height }\end{array}$ & $0,9-30 \mathrm{~m}$ & To be studied & $\begin{array}{l}\text { Simulation suing the similarity } \\
\text { methods }\end{array}$ \\
\hline 11 & Cut depth & $0,9-30 \mathrm{~m}$ & To be studied & $\begin{array}{l}\text { Simulation suing the similarity } \\
\text { methods }\end{array}$ \\
\hline 12 & $\begin{array}{l}\text { Ballast section } \\
\text { shoulder }\end{array}$ & $0,35 \mathrm{~m}$ & $0,35 \mathrm{~m}$ & Analogue is accepted [9] \\
\hline 13 & $\begin{array}{l}\text { Heat loss via the } \\
\text { adjoining rail } \\
\text { cross-sections }\end{array}$ & Rail bar & $\begin{array}{l}\text { Foam polystyrene end } \\
\text { insulation caps }\end{array}$ & Thickness at least $50 \mathrm{~mm}$ \\
\hline 14 & $\begin{array}{l}\text { Heat loss via he } \\
\text { fixing elements, } \\
\text { tie, ballast }\end{array}$ & $\begin{array}{l}\text { Tension of each intermediate } \\
\text { rail fastening bolt }- \text { at least } \\
100 \mathrm{Nm} \text { (terminal bolts) and } \\
70 \mathrm{Nm} \text { (insert bolts) }\end{array}$ & $\begin{array}{l}\text { Tension of each intermediate } \\
\text { rail fastening bolt at least } \\
100 \mathrm{Nm} \text { (terminal bolts) and } \\
70 \mathrm{Nm} \text { (insert bolts) }\end{array}$ & Analogue is accepted [1] \\
\hline 15 & Cloud amount & Natural & Natural & Analogue \\
\hline 16 & $\begin{array}{l}\text { Atmosphere } \\
\text { transparency }\end{array}$ & Natural & Natural & Analogue \\
\hline 17 & Wind & Natural & Natural & Analogue \\
\hline
\end{tabular}

depth, i.e. for the depth up to $1,0 \mathrm{~m}$ it is about $14 \%$ less. It was also proved that there is a wind shadow behind the rail, with transverse air flow direction to the axis. Thus, at a certain distance from the rail, in the shadow, the wind velocity gradually drops to 0 . For a R65 rail, the above distance changes from $720 \mathrm{~mm}$ to $900 \mathrm{~mm}$. This fact makes it possible to plan placing a freely-supported short rail on the concrete half-tie, designed for measuring the temperature of the previously unloaded rail bars for further scheduled laying in the continuous welded track.

In [16], before the beginning of the experimental studies, the simulation conditions were analyzed to obtain the similarity criterion. For this purpose, it was assumed that the flow of fluid in all points of the natural and simulated flows is described with the differential equation of motion of incompressible viscous fluid (Navier-Stokes equation). Then we will find the similarity criteria as four groups of non-dimensional values: homochronicity number $(\mathrm{H})$, Froude number (Fr), Euler number (E) and Reynolds number (Re).

It was demonstrated that no whirls occur in the cuts which are at least 2,0 m deep, or they can be considered whirls in which the velocity of air current only slows down. This is the factor influencing the rail temperature which in the cuts is higher than on the embankments.

The studies [16] proved that the thermal energy is carried mostly by the beams with a wave length of $0,4 \div 0,8 \mu \mathrm{m}$ and IR beams with a wave length of $0,8 \div 3,0 \mu \mathrm{m}$. However, the earth surface radiates thermal energy with a wave length of $9 \div 12 \mu \mathrm{m}$. The numerical depth of the ground layer is very small for long-wave radiation (fraction of a millimetre) and too big (up to a few centimetres) for short-wave radiation. In [16, 17], the nature of the diurnal change of the radiation balance of the ground surface was determined. It was determined with the periodic function that changes the sign twice a day - in the morning and in the evening, while a zero balance is observed not during sunrise or sunset, but 
when it is $10 \div 15^{\circ}$ above the horizon. This fact is critical for determining the time to begin measuring the thermal distortion of short rails, while it is the time when the rail temperature is equal to the air temperature. Since $1^{\circ}$ above the horizon corresponds to one Sun disc, and the time for which the Sun moves by $1^{\circ}$ is $4 \mathrm{~min}$, thermal distortion of short rails shall be recorded at the test bench not later than $40 \div 60$ min after the sunset.

Thus, four 1,0 m high embankments and four 1,0 m deep cuts, one for each of the chosen exposure direction, should be arranged at the test bench.

\section{Conclusions}

On the basis of the performed studies, the design of a test bench for thermometric studies of welded track was elaborated on. The findings of field tests are to be verified by comparing them with the results of calculations made using software complex based on the finite element method [18].

\section{References}

1. V. Albrekht, A. Kogan, Continuous welded rails, Transport, (2000)

2. E. Danilenko, Railway track: design, installation and operation, Inpress, (2010)

3. V. Rubkin, M. Arbuzov, Science and progress of transport, 9, 74-77 (2005)

4. V. Pavlenko, Transport of the Russian Federation, 5(36), $30-31$ (2011)
5. A. Wegner, Proceedings of $10^{\text {th }}$ International Heavy Haul Association Conference, New Delhi, India, 160 - 168, (2013)

6. J. Zakeri, H. Xia, J. Fan, Latin American Journal of Solids and Structures, 6, 89 - 104, (2009)

7. J. Zakeri, H. Xia, J. Fan, Journal of Northern Jiaotong University, 24(1), 50-55, (2000)

8. D. Bowness, A. Lock, W. Powrie, J. Priest, D. Richards, Proceedings of the IMechE, Part F: J. Rail and Rapid Transport, 221(F1), 13-22 (2007)

9. Technical requirements of the operation, repair and installation of CW rails in Ukraine, TSP0266, Kiev, (2012).

10. Technical recommendations of determination of $\mathrm{CW}$ rails temperature, Transport, (1980)

11. M. Kirpichev, Theory of similarity, Science, (1953)

12. L. Andreeva, Protection of railway track and structures from natural factors, Moscow, (2016)

13. A. Petrov, Construction and Architecture, 3, 582-584 (2010)

14. A. Komarov, M. Istrapilovich, I. Veronskaya, Scientific Works of Novosibirsk Railway Institute, 130, 168-176 (1971)

15. P. Tverskoy, Meteorology, Gidrometeoizdat, (1951)

16. D. Laihtman, A. Chudnoskij, Physics of surface layer, Gostechizdat, (1949)

17. A. Petrov, G. Petrova, I. Panchishkina, Proc. $12^{\text {th }}$ Int. Conf. Atm. Electricity. Versailles, France, 5, 2003.

18. H. Lee. Finite Element Simulations with ANSYS Workbench 16, SDC Publication (2015) 